\title{
ORIGINAL ARTICLE \\ White sweet potato ameliorates hyperglycemia and regenerates pancreatic islets in diabetic mice
}

\author{
Chun-Kuang Shih', Chiao-Ming Chen², Viola Varga', Liang-Chen Shih', \\ Peng-Ru Chen², Shu-Fang Lo ${ }^{3}$, Lie-Fen Shyur ${ }^{4}$ and Sing-Chung Li'* \\ ISchool of Nutrition and Health Science, College of Nutrition, Taipei Medical University, Taipei, Taiwan; \\ 2Department of Food Science, Nutrition, and Nutraceutical Biotechnology, Shih Chien University, Taipei, \\ Taiwan; ${ }^{3}$ Department of Agronomy, Chiayi Agricultural Experiment Station, Taiwan Agricultural Research \\ Institute, Chiayi, Taiwan; ${ }^{4}$ Agricultural Biotechnology Research Center, Academia Sinica, Taipei, Taiwan
}

\section{Popular scientific summary}

- The 30\%-T or 5\%-L of WSP had lower plasma glucose, insulin, AUC, HOMA-IR, alanine transaminase, triglyceride, and tumor necrosis factor alpha in diabetic mice.

- The DM+30\%-T or DM+5\%-L of WSP had significantly restored Langerhans's area by approximately $30 \%$.

- The 5\%-L of WSP increased insulin sensitivity possibly via the insulin-signaling pathway and reduce blood glucose levels in diabetic mice.

\section{Abstract}

Background: White sweet potato (WSP) has many potential beneficial effects on metabolic control and on diabetes-related insulin resistance. The antihyperglycemic effects of Tainung No. 10 (TNG10), a variety of WSP in Taiwan, warrant investigation.

Objective: To investigate the antidiabetic activity of WSP (Ipomoea batatas L. TNG10) and the mechanisms for interventions using whole leaves or tubers of WSP in diabetic mice.

Design: Mice were co-administered with streptozotocin and nicotinamide to induce diabetes and then treated with an experimental diet including either $10 \%$ WSP tuber (10\%-T) and 30\% WSP tuber (30\%-T) or $0.5 \%$ WSP leaf $(0.5 \%-\mathrm{L})$ and $5 \%$ WSP leaf $(5 \%-\mathrm{L})$. After 8 weeks' treatment, their plasma glycemic parameters, lipid profiles, and inflammatory marker were analyzed. Their pancreases were removed for histopathologic image analysis; proteins were also extracted from their muscles for phosphoinositide 3-kinase pathway analysis.

Results: The 30\%-T or 5\%-L mice had lower plasma glucose, insulin, glucose area under the curve (AUC), homeostatic model assessment of insulin resistance (HOMA-IR), alanine transaminase, triglyceride, and tumor necrosis factor alpha levels. In all diabetic mice, their Langerhans's area was reduced by $60 \%$; however, after $30 \%$ WSP-T or 5\% WSP-L diets, the mice demonstrated significant restoration of the Langerhans's areas (approximately 30\%). Only in 5\%-L mice, slightly increased expression of insulin-signaling pathway-related proteins, phosphorylated insulin receptor and protein kinase B and membrane glucose transporter 4 was noted.

Conclusions: WSP has antihyperglycemic effects by inducing pancreatic islet regeneration and insulin resistance amelioration. Therefore, WSP has potential applications in dietary diabetes management.

Keywords: white sweet potato; antidiabetic; antihyperglycemic; pancreatic islets; insulin sensitivity

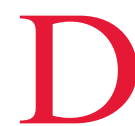
iabetes is one of the most prominent public health concerns of the 21 st century and is characterized by the effects of either increasing insulin resistance or impairing glucose tolerance (1). According to the latest global estimate from the International Diabetes Federation, 415 million people had diabetes in 2015 , and this number is expected to reach 642 million by 2040 (2). Glucose homeostasis is maintained by the fine orchestration of insulin 
secretion and activity both for promoting glucose transport into muscle and adipocytes and for inhibiting liver glucose output. Defects in insulin signaling impair glucose utilization and are believed to be a critical factor in insulin resistance pathogenesis (3). Resistance to these effects of insulin is a classic pathogenic feature of obesity and type 2 (non-insulin-dependent) diabetes mellitus (T2DM) $(4,5)$. In T2DM, insulin resistance is initially compensated by increased secretion of insulin; however, this prolonged hyperinsulinemia leads to progressive $\beta$-cell exhaustion and degradation (6). The co-administration of streptozotocin (STZ) and nicotinamide (NA) can be used to induce T2DM animal models; this is because $\mathrm{STZ}$ causes pancreatic $\beta$-cell damage, whereas NA partially protects insulin-secreting cells against STZ damage (7-9).

The phosphoinositide 3-kinase (PI3K) signaling pathway, a signal transduction system downstream of an insulin receptor (IR), is a key factor in the translocation of the glucose transporter protein from intracellular compartments to plasma membrane (10). IRs are present in most mammalian cells, and insulin-IR binding results in the activation of several phosphorylation-dephosphorylation cascades (11). Autophosphorylation of the intracellular $\beta$-subunit of IRs activates tyrosine kinase, which catalyzes multiple IR substrate (IRS) protein phosphorylation (12). Disruption in IRS protein phosphorylation or impaired PI3K recruitment from the cytosol, which results in PI3K inactivation, causes insulin resistance, followed by diabetes (13). Protein kinase B (Akt; also called alpha serine/threonine protein kinase) activation by growth factors occurs in a PI3K-dependent manner. Activated Akt has critical roles in cellular processes, such as apoptosis, cell survival, and cell progression, as well as T2DM pathogenesis (10).

Activated Akt, which is primarily expressed in insulin-responsive tissues, promotes glucose transporter 4 (GLUT4) translation (14). Akt possibly influences insulin signal transmission and glucose transport (15). Insulin increases glucose uptake in cells by stimulating GLUT4 translocation from the intracellular sites to the cell surface; moreover, up to $75 \%$ of insulin-dependent glucose disposal occurs in skeletal muscle (15). Reducing GLUT4 expression and translocation in a cell may result reduced glucose uptake and thus cause insulin resistance (16). Mulberry leaf extract stimulates glucose uptake and GLUT4 translocation to the plasma membrane of adipocytes through the PI3K-mediated signaling pathway (17). A flavonoid isolated from rutin enhances insulin-dependent receptor kinase activity and GLUT4 translocation in differentiated muscle myotubes and thereby improves glucose uptake (18). Mango leaf extract affects glucose and lipid homeostasis in vitro and in vivo through the PI3K/ Akt and Adenosine monophosphate-activated protein kinase (AMPK) signaling pathways (19). Bamboo leaf extract treatment could increase the phosphorylated Akt level in renal tissues of rats with diabetes (20). Therefore, insulin-like activity, such as the stimulation of glucose uptake by skeletal muscle through PI3K/Akt pathways, may be crucial in regulating blood glucose level.

White sweet potato (WSP; Ipomoea batatas L.) belongs to the Convolvulaceae family. WSP extracts have antidiabetic activity in both insulin-deficient and -resistant diabetic models (21-25). In patients with T2DM, WSP tuber extract effectively reduced insulin resistance as well as fibrinogen, fasting plasma glucose, and low-density lipoprotein-cholesterol levels (26-28). In our previous clinical trial, meal replacement therapy using whole tuber of WSP Tainung No. 10 (TNG10) - a new WSP cultivar that can provide $15.5 \mathrm{~g}$ of fiber per $100 \mathrm{~g}$ and has an average glycemic index of 36.2 - was found to reduce energy and glucose absorption in the intestines (29). WSP incorporated into enteral formulas also can improve nutrition status and glycemic control in elderly diabetic patients (30).

Thus far, animal studies on the use of native WSP tubers (WSP-T) or leaves (WSP-L) as a functional ingredient for the management of non-insulin-dependent diabetic mice have been scant. This study thus evaluated the effects of various WSP-T or WSP-L dosages on antidiabetic activity involving PI3K/Akt pathway activation in mice with STZ-NA-induced diabetes. These results may provide insights into the use of WSP as a potential functional food for treating T2DM. Moreover, the influence of WSP on islet function and morphology was investigated.

\section{Materials and methods}

\section{Plant materials}

Fresh mature I. batatas L. TNG10, a starch-rich WSP variety, were harvested from a farm in the Chiayi Agricultural Experiment Station, Taiwan. The WSP TNG10 tuber were first washed and then sliced (thickness: 3-5 mm). The WSP leaves were washed and air-dried. Both sliced sweet potatoes and treated leaves were lyophilized and ground using 200 mesh $(75 \mu \mathrm{m})$ for use in animal diet.

\section{Experimental design and treatment schedule}

Male Institute of Cancer Research (ICR) mice $(n=30$, age: 4 weeks) were obtained from BioLASCO Taiwan (Taipei, Taiwan). Taipei Medical University approved the use of these laboratory animals (LAC-100-0202). The mice were housed throughout the feeding experiment in a room maintained on a 12-h light-dark cycle at a constant temperature of $24^{\circ} \mathrm{C}$ with relative humidity of $65 \pm 15 \%$. They were allowed free access to food and water and were fed the American Institute of Nutrition (AIN)-93G (31). After 2 weeks of adaptation, diabetes mellitus (DM) was induced in the mice by two intraperitoneal injections of NA (120 mg/kg body weight [b.w.]) plus STZ $50 \mathrm{mg} / \mathrm{kg}$ 
b.w.; Sigma, Saint Louis, MO, USA). NA, dissolved in saline, was injected intraperitoneally $15 \mathrm{~min}$ before the administration of STZ, which was freshly dissolved in citrate buffer ( $\mathrm{pH} 4.5$ ) to induce diabetes at 1-day interval $(9,32)$. Normal saline $(0.9 \% \mathrm{NaCl})$ was used as a vehicle injection for the normal control (NC) group. During the experimental period, the animals' food intake and body weight were monitored once a week. A mouse was considered hyperglycemic when its fasting plasma glucose concentration was $>180 \mathrm{mg} / \mathrm{dL}$ at 2 weeks after the last induction date. The mice were divided into six experimental groups comprising five animals each: NC, DM, DM plus $10 \%$ tuber (DM+10\%-T), DM plus $30 \%$ tuber $(\mathrm{DM}+30 \%-\mathrm{T})$, DM plus $0.5 \%$ leaf $(\mathrm{DM}+0.5 \%-\mathrm{L})$, and $\mathrm{DM}$ plus $5 \%$ leaf $(\mathrm{DM}+5 \%-\mathrm{L})$. The compositions of the experimental diets are detailed in Table 1. Both NC and DM groups received an AIN-93G diet. The 10\%-T and 30\%-T groups received an AIN-93G diet containing 100 or $300 \mathrm{~g} / \mathrm{kg}$ of WSP-T. Moreover, the $0.5 \%-\mathrm{L}$ and $10 \%$-L groups received an AIN-93G diet containing 5 or $50 \mathrm{~g} / \mathrm{kg}$ of WSP-L, respectively. All experimental diets were equal in terms of calories (4.16 calories per gram), equal nutrients composition (carbohydrate: protein: fat $=63.5 \%: 20.5 \%: 16 \%$ ), and fibers to ensure that no blood marker changes due to energy or cellulose imbalance occurred.

\section{Blood markers}

A glucose tolerance test was conducted before the completion of the experiment. The mice were starved overnight, and the blood samples were taken from the tail vein (time 0$)$. A glucose challenge was given $(1 \mathrm{~g}$ glucose $/ \mathrm{kg}$ b.w.), and other blood samples were obtained after 30 ,
60,90 , and 120 min by tail vein sampling (33). Plasma glucose concentrations were determined; the area under the curve (AUC) for blood glucose was also calculated (34). After 8 weeks of these diets, the mice were starved overnight and then anesthetized in their sleep with isoflurane. Blood was collected in non-anticoagulant tubes and tubes containing ethylenediaminetetraacetic acid. Serum and plasma were prepared and stored at $-20^{\circ} \mathrm{C}$ for further insulin and lipid measurement. Blood was also collected in tubes containing heparin, and plasma was prepared and stored at $-20^{\circ} \mathrm{C}$ for glucose measurement. The homeostatic model assessment-insulin resistance (HOMA-IR) index was calculated as (fasting plasma glucose $\times$ plasma insulin/22.5) to assess insulin resistance (35). Plasma insulin levels were measured using a mouse insulin enzymelinked immunosorbent assay kit (Mercodia, Uppsala, Sweden). Tumor necrosis factor alpha (TNF- $\alpha$ ) levels were determined by using an enzyme-linked immunosorbent assay (BioLegend, San Diego, CA, USA) according to the manufacturer's instructions. The levels of other blood biomarkers, namely, alanine transaminase (ALT), triglyceride (TG), and total cholesterol (TC), were analyzed from a $0.1 \mathrm{~mL}$ serum sample in the National Laboratory Animal Center (Taipei, Taiwan).

\section{Western blotting}

The gastrocnemius muscles were homogenized in a modified Radioimmunoprecipitation assay buffer (RIPA) buffer (0.5 M Tris- $\mathrm{HCl}$ at $\mathrm{pH} 7.4,1.5 \mathrm{M}$ sodium chloride, $2.5 \%$ deoxycholic acid, $10 \% \mathrm{NP}-40$, and $10 \mathrm{mM}$ ethylenediaminetetraacetic acid) and 10\% protease and phosphatase inhibitor cocktail (Sigma, Saint Louis, MO, USA). The homogenates were centrifuged at $10,000 \mathrm{~g}$ at $4^{\circ} \mathrm{C}$ for

Table 1. Percentage composition of the experimental diet

\begin{tabular}{|c|c|c|c|c|c|}
\hline \multirow[t]{2}{*}{ Content $(\mathrm{g} / \mathrm{kg})$} & \multicolumn{5}{|c|}{ Diets } \\
\hline & $\begin{array}{l}\text { Normal control (NC)/ } \\
\text { diabetes mellitus (DM) }\end{array}$ & $\begin{array}{l}\text { DM + } 10 \%-\mathrm{T}(10 \% \text { white } \\
\text { sweet potato [WSP] tuber) }\end{array}$ & $\begin{array}{c}\mathrm{DM}+30 \%-\mathrm{T} \\
\text { (30\% WSP tuber) }\end{array}$ & $\begin{array}{c}\mathrm{DM}+0.5 \%-\mathrm{L} \\
(0.5 \% \text { WSP leaf })\end{array}$ & $\begin{array}{c}\mathrm{DM}+5 \%-\mathrm{L} \\
(5 \% \text { WSP leaf })\end{array}$ \\
\hline Powdered tubers & - & 100 & 300 & - & - \\
\hline Powdered leaves & - & - & - & 5 & 50 \\
\hline Corn starch & 397.4 & 338.6 & 220.9 & 397.4 & 388.4 \\
\hline Casein & 200 & 195.1 & 185.3 & 199 & 189.5 \\
\hline Dextrinized cornstarch & 132 & 132 & 132 & 132 & 132 \\
\hline Sucrose & 100 & 94.8 & 84.4 & 100 & 100 \\
\hline Soybean oil & 70 & 70 & 70 & 70 & 70 \\
\hline Fiber & 50 & 42.7 & 28.2 & 48 & 30 \\
\hline AIN-93 mineral mix & 35 & 35 & 35 & 35 & 35 \\
\hline AIN-93-vitamin mix & 10 & 10 & 10 & 10 & 10 \\
\hline L-Cysteine & 3 & 3 & 3 & 3 & 3 \\
\hline Choline bitartrate & 2.5 & 2.5 & 2.5 & 2.5 & 2.5 \\
\hline Tert-butylhydroquinone (mg/kg) & 0.014 & 0.014 & 0.014 & 0.014 & 0.014 \\
\hline
\end{tabular}

Each experimental chow diet has equal calories (4.16 calories per g) and equal nutrients composition (carbohydrate: protein: fat $=63.5 \%: 20.5 \%: 16 \%$ ). 
$15 \mathrm{~min}$, and the supernatants were collected. For demonstrating GLUT4 expression in the membrane, the muscle lysate was prepared using a Mem-PER kit (Thermo Fisher Scientific, Waltham, MA, USA) to enrich the membrane proteins. Protein concentrations in each sample were quantified using a commercial assay kit (Bio-Rad DC Protein Assay kit, Bio-Rad Laboratories, Hercules, CA, USA) with bovine serum albumin as a standard. Equal amounts of proteins $(40 \mu \mathrm{g})$ were denatured and separated through $10 \%$ sodium dodecyl sulfate polyacrylamide gel electrophoresis and then transferred onto a polyvinylidene difluoride transfer membrane (Amersham Biosciences, Little Chalfont, Bucks, UK). These blots were then incubated with primary antibodies, namely anti-IR (ab69508, WB 1:250; Abcam, MA, USA), anti-phosphorylated IR Thr1146 (p-IR-Thr1146, 3021, WB 1:1000; Cell signaling, MA, USA), anti-Akt (2938, WB 1:1000; Cell signaling, MA, USA), anti-phosphorylated Akt (p-Akt; 9018, WB 1:1000; Cell signaling, MA, USA), and anti-GLUT4 (ab654, WB 1:2000; Abcam) antibodies, at $4^{\circ} \mathrm{C}$ overnight and then with secondary antibodies, namely goat anti-rabbit or goat antimouse (Abcam) antibodies, at a 1:5000 ratio at room temperature for $1 \mathrm{~h}$. The binding of antibodies was determined using FAST 5-bromo-4-chloro-3-indolyl phosphate/nitro blue tetrazolium as the substrate of the secondary antibody-conjugated alkaline phosphatase. The band density was quantified using the analysis software Quantity One 1-D (Bio-Rad, Hercules, CA, USA). All controls for Western blotting were applied to ensure antibody specificity and protein consistency.

\section{Pathological tissue preparation}

The pancreas and liver tissues isolated from the sacrificed animals were fixed in 10\% neutral buffered formalin solution, dehydrated by passing through a graded series of alcohol, and embedded in paraffin blocks; these blocks were then cut into $5-\mu \mathrm{m}$-thick sections by using a Leica RM 2245 rotary microtome (Leica Microsystems, Wetzlar, Germany). These sections were stained using hematoxylin and eosin (H\&E). A pathologist blinded to the treatments performed the histological evaluation. The photomicrographs of each tissue section were observed on the EVOS FL Imaging System (Thermo Fisher Scientific, Waltham, MA, USA) and then analyzed using Image J (http://rsb. info.nih.gov/ij/) for area percentage.

\section{Statistical analysis}

Numerical data are presented as means \pm standard deviations. Statistical evaluation was performed using one-way analysis of variance (ANOVA), followed by Duncan's multiple range test. All data analyses were performed using SPSS (version 19; SPSS Inc., Chicago, IL, USA). Differences were considered significant at $P<0.05$.

\section{Results}

\section{Body weight, food intake, and feed efficiency ratio}

The body weight, weight gains, food intakes, and feed efficiency ratios (FERs) of the mice are presented in Table 2. The weight gain was significantly lower in the DM group than in other control groups $(P<0.05)$. The consumption of different dosage of tuber or leaf did not influence the final body weight and weight gain in diabetic mice fed the experimental diets. The FER was significantly higher in $\mathrm{DM}+10 \%-\mathrm{T}, \mathrm{DM}+30 \%-\mathrm{T}, \mathrm{DM}+0.5 \%-\mathrm{L}$ mice and $\mathrm{DM}+5 \%-\mathrm{L}$ than in the DM group $(P<0.05)$.

\section{Biochemical findings}

After the 8-week intervention with different experimental diets, the groups exhibited no significant differences in the average body weight, organ weight, or feed efficiency. The mean fasting blood glucose was $153.8 \pm 11.5$ and $287.4 \pm$ $14.4 \mathrm{mg} / \mathrm{dL}$ in the NC and DM mice, respectively. All mice with STZ-NA-induced diabetes exhibited mild hyperglycemia. The blood glucose level was $262.9 \pm 7.9$ and $270.1 \pm$ $11.6 \mathrm{mg} / \mathrm{dL}$ in $\mathrm{DM}+10 \%-\mathrm{T}$ or $\mathrm{DM}+0.5 \%-\mathrm{L}$ mice, respectively, whereas it was $218.8 \pm 11.5$ and $211.6 \pm 11.5 \mathrm{mg} / \mathrm{dL}$ in $\mathrm{DM}+30 \%-\mathrm{T}$ or $\mathrm{DM}+5 \%-\mathrm{L}$ mice, respectively. Thus, the

Table 2. Body weight, food intake, and feed efficiency ratio in the mice fed with experimental diets

\begin{tabular}{lcccccc}
\hline Group & $\begin{array}{c}\text { Normal } \\
\text { control (NC) }\end{array}$ & $\begin{array}{c}\text { Diabetes } \\
\text { mellitus (DM) }\end{array}$ & $\begin{array}{c}\text { Diabetes mellitus } \\
\text { plus 10\% tuber } \\
(\mathrm{DM}+10 \%-\mathrm{T})\end{array}$ & $\begin{array}{c}\text { Diabetes mellitus } \\
\text { plus 30\% tuber } \\
(\mathrm{DM}+30 \%-\mathrm{T})\end{array}$ & $\begin{array}{c}\text { Diabetes mellitus } \\
\text { plus 0.5\% leaf } \\
(\mathrm{DM}+0.5 \%-\mathrm{L})\end{array}$ & $\begin{array}{c}\text { Diabetes mellitus } \\
\text { plus 5\% leaf } \\
(\mathrm{DM}+5 \%-\mathrm{L})\end{array}$ \\
\hline Initial body weight (g) & $33.4 \pm 1.0$ & $34.9 \pm 1.5$ & $34.7 \pm 2.5$ & $32.0 \pm 2.0$ & $36.0 \pm 2.5$ & $34.4 \pm 3.2$ \\
Final body weight (g) & $40.9 \pm 2.4$ & $39.4 \pm 1.5$ & $43.0 \pm 3.6$ & $43.3 \pm 5.3$ & $47.1 \pm 6.9$ & $41.8 \pm 6.2$ \\
Weight gain (g/day) & $0.152 \pm 0.04$ & $0.080 \pm 0.020$ & $0.180 \pm 0.044^{*}$ & $0.202 \pm 0.065^{*}$ & $0.198 \pm 0.059^{*}$ & $0.192 \pm 0.038^{*}$ \\
Food intake (g/day) & $4.50 \pm 0.54$ & $5.50 \pm 0.95$ & $5.11 \pm 0.52$ & $4.80 \pm 0.86$ & $4.70 \pm 0.76$ & $4.78 \pm 0.85$ \\
Feed efficiency ratio (\%) & $3.22 \pm 0.23$ & $1.45 \pm 0.16$ & $3.52 \pm 0.27^{*}$ & $4.21 \pm 0.25^{* a}$ & $4.21 \pm 0.22^{*}$ & $4.02 \pm 0.28^{*}$ \\
\hline
\end{tabular}

Asterisks indicate significance level compared to DM group. Letter 'a' indicates significance level to DM + 10\%-T group. All values are presented as means \pm standard deviation $(n=5)$. Statistical evaluation was performed using one-way ANOVA, followed by Duncan's multiple range test, $P<0.05$. Feed efficiency ratio $(\mathrm{FER}, \%)=($ Body weight gain $(\mathrm{g} /$ day $) /$ food intake $(g /$ day $)) \times 100$. 
higher the tuber $(30 \%-\mathrm{T})$ or leaf $(5 \%-\mathrm{L})$ dosage, the more was the pronounced reduction effect on fasting blood glucose levels, AUC and glucose tolerance test, compared with AIN-93G diet alone (Figs. 1a, b and 2). The AUC derived from the glucose tolerance test was next used to diagnose impaired glucose tolerance. Compared with that of DM mice $(100 \%)$, the AUC of $\mathrm{DM}+5 \%-\mathrm{L}, \mathrm{DM}+0.5 \%-\mathrm{L}$, $\mathrm{DM}+30 \%-\mathrm{T}$, and $\mathrm{DM}+10 \%-\mathrm{T}$ mice decreased to $24 \%$, $53 \%, 38 \%$, and $79 \%$, respectively. Thus, both $\mathrm{DM}+5 \%-\mathrm{L}$ and $\mathrm{DM}+30 \%-\mathrm{T}$ mice demonstrated significant reduction in the AUC (Fig. 1b). After intervention, the plasma insulin levels slightly increased, by a factor of 0.71 , in $\mathrm{DM}+5 \%-\mathrm{L}$ and $\mathrm{DM}+30 \%-\mathrm{T}$ mice (Fig. 1c). Moreover, HOMA-IR indicated significantly higher insulin resistance in DM mice than in the other groups. Similarly, compared with DM mice, HOMA-IR considerably improved in $\mathrm{DM}+10 \%$-T (0.83-fold improvement), DM+30\%-T (0.54fold improvement), $\mathrm{DM}+0.5 \%-\mathrm{L}$ ( 0.83 -fold improvement), and DM+5\%-L (0.53-fold improvement) mice (Fig. 1d).
Taken together, these results indicate that our experimental diets with higher percentages of tuber or leaf from WSP improved the glycemic markers in the diabetic mice.

In mice, DM induction increased plasma ALT levels by up to $120.53 \pm 45.96 \mathrm{U} / \mathrm{L}$ (Table 3). However, ALT decreased by a factor of 0.54 and $0.31 \mathrm{in} \mathrm{DM}+30 \%-\mathrm{T}$ and $\mathrm{DM}+10 \%-\mathrm{T}$ mice, respectively. Similarly, in $\mathrm{DM}+0.5 \%-\mathrm{L}$ and $\mathrm{DM}+5 \%-\mathrm{L}$ mice these decreases were by a factor of $0.37-0.43$. DM caused TG levels to increase to $151.13 \pm$ $47.57 \mathrm{mg} / \mathrm{dL}$ in DM mice; nevertheless, in WSP-T or WSP-L-treated mice, the TG levels reduced by a factor of $0.3-0.63$. However, no significant intergroup differences were observed in the ALT or TG levels between the WSP-T- or WSP-L-administered mice. The TC also did not differ significantly among groups. DM mice exhibited increased levels of the inflammatory marker TNF- $\alpha$ $(45.18 \pm 5.72 \mathrm{pg} / \mathrm{mL})$, which significantly decreased after intervention with higher dosage of WSP-T or WSP-L; this decrease was significant, by a factor of approximately (a)

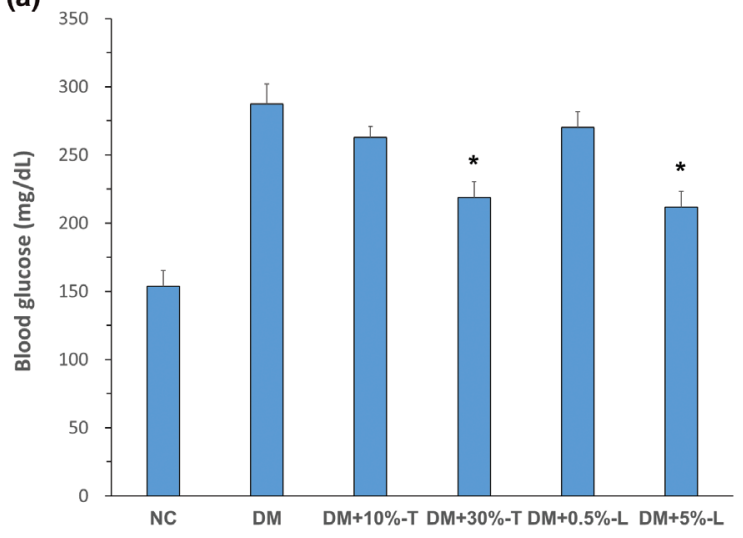

(c)

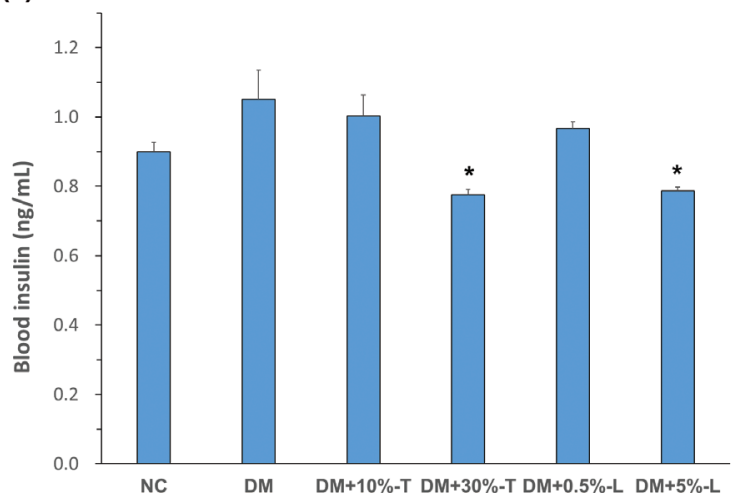

(b)

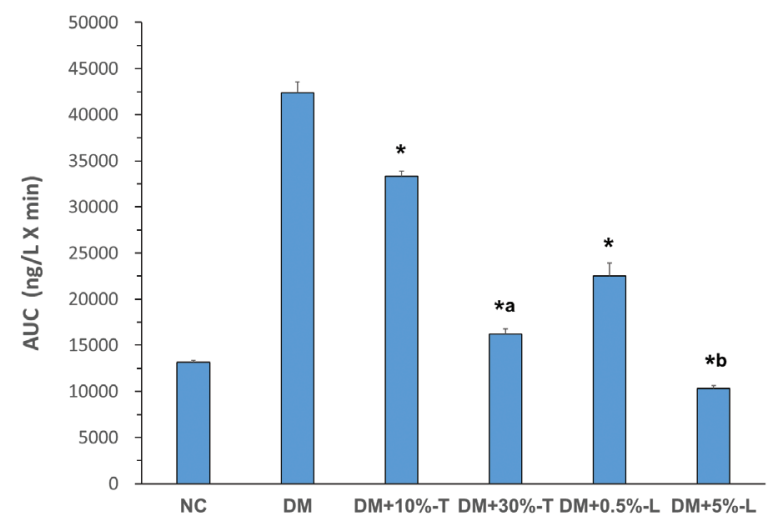

(d)

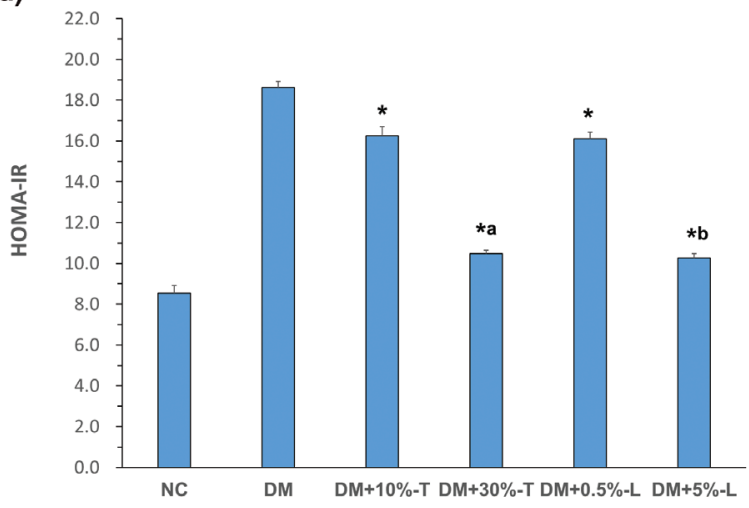

Fig. 1. Blood glucose and insulin index analysis in various groups. (a) Fasting blood glucose concentration. (b) Glucose area under the curve (AUC 0-120 min). (c) Blood insulin level. (d) The homeostatic model assessment-insulin resistance (HOMA-IR) in various groups after 8 weeks of the white sweet potato intervention. Asterisks indicate significance level compared to DM group. Letter 'a' indicates significance level to DM + 10\%-T group. Letter ' $\mathrm{b}$ ' indicates significance level to DM $+0.5 \%-\mathrm{L}$ group. All values are presented as means \pm standard deviation $(n=5)$. Statistical evaluation was performed using one-way ANOVA, followed by Duncan's multiple range test, $P<0.05$. 


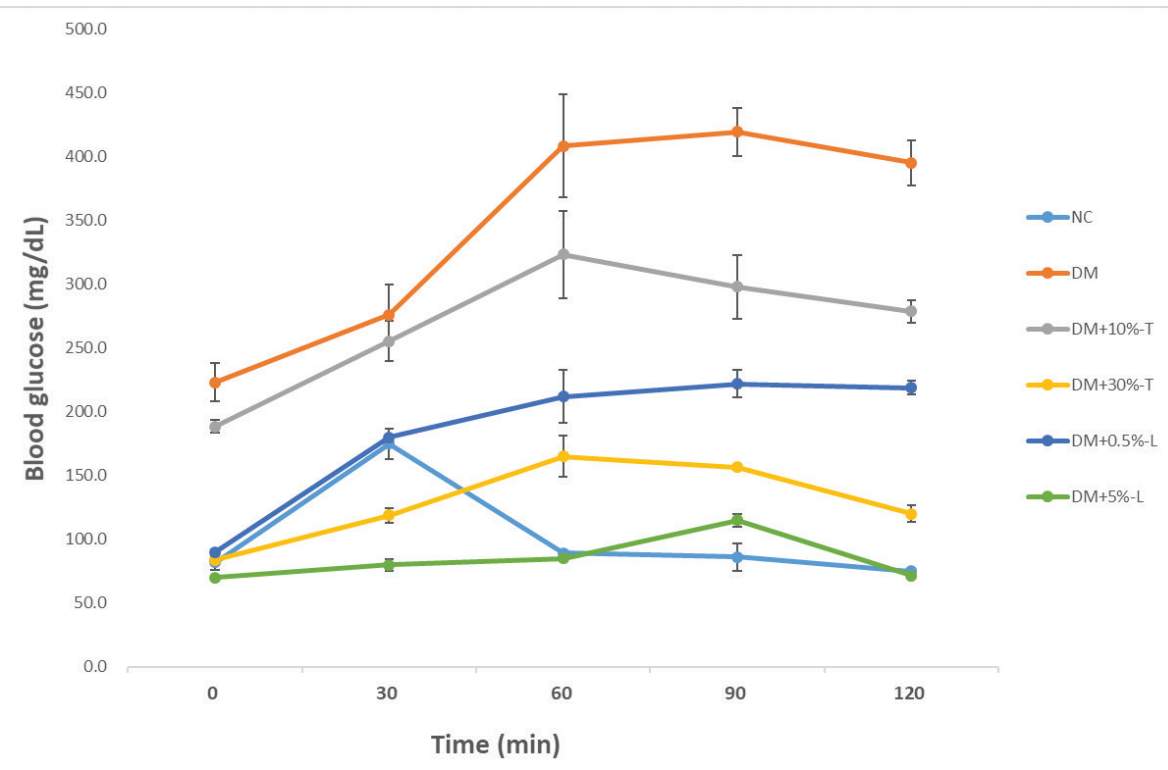

Fig. 2. Glucose tolerance test in various experimental diet. All values are presented as means \pm standard deviations $(n=5)$. Plasma blood glucose levels were determined in different time (0-120 min). NC, normal control; DM, diabetes mellitus; DM+10\%-T, diabetes mellitus plus 10\% tuber; DM+30\%-T, diabetes mellitus plus 30\% tuber; DM+0.5\%-L, diabetes mellitus plus $0.5 \%$ leaf; $\mathrm{DM}+5 \%$-L, diabetes mellitus plus $5 \%$ leaf.

Table 3. Mouse blood biochemistry test after 8 weeks of experimental diet intervention

\begin{tabular}{|c|c|c|c|c|c|c|}
\hline Group & $\begin{array}{c}\text { Normal } \\
\text { control (NC) }\end{array}$ & $\begin{array}{c}\text { Diabetes } \\
\text { mellitus (DM) }\end{array}$ & $\begin{array}{l}\text { Diabetes mellitus } \\
\text { plus } 10 \% \text { tuber } \\
\text { (DM }+10 \%-T)\end{array}$ & $\begin{array}{l}\text { Diabetes mellitus } \\
\text { plus 30\% tuber } \\
\text { (DM + 30\%-T) }\end{array}$ & $\begin{array}{l}\text { Diabetes mellitus } \\
\text { plus } 0.5 \% \text { leaf } \\
\text { (DM }+0.5 \%-\mathrm{L})\end{array}$ & $\begin{array}{l}\text { Diabetes mellitus } \\
\text { plus } 5 \% \text { leaf } \\
\text { (DM }+5 \%-L)\end{array}$ \\
\hline Alanine transaminase (ALT) (U/L) & $50.34 \pm 15.85$ & $120.53 \pm 45.96$ & $65.03 \pm 22.74^{*}$ & $37.76 \pm 7.4 I^{*}$ & $44.01 \pm 12.76^{*}$ & $51.48 \pm 11.68^{*}$ \\
\hline Triglyceride (TG) (mg/dL) & $86.34 \pm 23.46$ & $|5| .13 \pm 47.57$ & $95.42 \pm 30.85$ & $72.44 \pm 27.05^{*}$ & $45.13 \pm 16.18^{*}$ & $53.50 \pm 18.55^{*}$ \\
\hline Total cholesterol (TC) (mg/dL) & $160.72 \pm 44.62$ & $158.98 \pm 23.36$ & $210.02 \pm 44.08$ & $146.76 \pm 23.15$ & $175.30 \pm 41.86$ & $148.62 \pm 41.98$ \\
\hline Tumor necrosis factor alpha (TNF- $\alpha)(p g / m L)$ & $29.37 \pm 8.64$ & $45.18 \pm 5.72$ & $42.22 \pm 8.12$ & $39.48 \pm 8.23^{*}$ & $43.11 \pm 8.91$ & $29.86 \pm 5.24^{* a}$ \\
\hline
\end{tabular}

Asterisks indicate significant difference compared to DM group. Letter ' $a$ ' indicates significance level to DM + 0.5\%-L group. All values are presented as means \pm standard deviations $(n=5)$. Statistical evaluation was performed using one-way ANOVA, followed by Duncan's multiple range test, $P<0.05$.

0.66 , after intervention with $5 \%$-L $(29.86 \pm 5.24 \mathrm{pg} / \mathrm{mL})$ compared with the DM group.

\section{Histological findings}

H\&E staining of liver tissue section, observed at a $100 \times$ magnification, revealed that DM mice demonstrated greater liver cytoplasmic vacuoles and inflammatory cell infiltration compared with mice in the other groups. The different dosage of WSP-T or WSP-L used in DM mice has slight morphological or structural changes in the liver tissue (Fig. 3); however, the photomicrographs in different concentrations of WSP-T or WSP-L were difficult to quantify by pathology software analysis.

The histology of pancreatic islets was normal in the NC group. The H\&E-stained histological sections of pancreas tissues of DM mice consistently revealed degenerative and necrotic changes and shrunken sections in the islets of Langerhans (Fig. 4). The nuclei of necrotic cells indicated pyknosis or marginal hyperchromasie. The results of semi-quantitative analysis from $\mathrm{H} \& \mathrm{E}$ staining are presented in Fig. 4b. The proportion of Langerhans's area in the photomicrographs was calculated using ImageJ. Langerhans's area was reduced by $60 \%$ in DM mice, but $\mathrm{DM}+30 \%-\mathrm{T}$ or $\mathrm{DM}+5 \%-\mathrm{L}$ mice demonstrated significantly restored Langerhans's area by approximately $30 \%$.

\section{Western blotting findings}

We then explored whether the antidiabetic activity of the WSP-T or WSP-L was involved in the PI3K/Akt pathway. Thus, we evaluated the expression of candidate proteins, such as phosphorylated and unphosphorylated IR and $\mathrm{Akt}$, in the aforementioned pathway as well as translocation of GLUT4 vesicles from cytosol to the cell membrane in muscles (Fig. 5). No significant differences were 

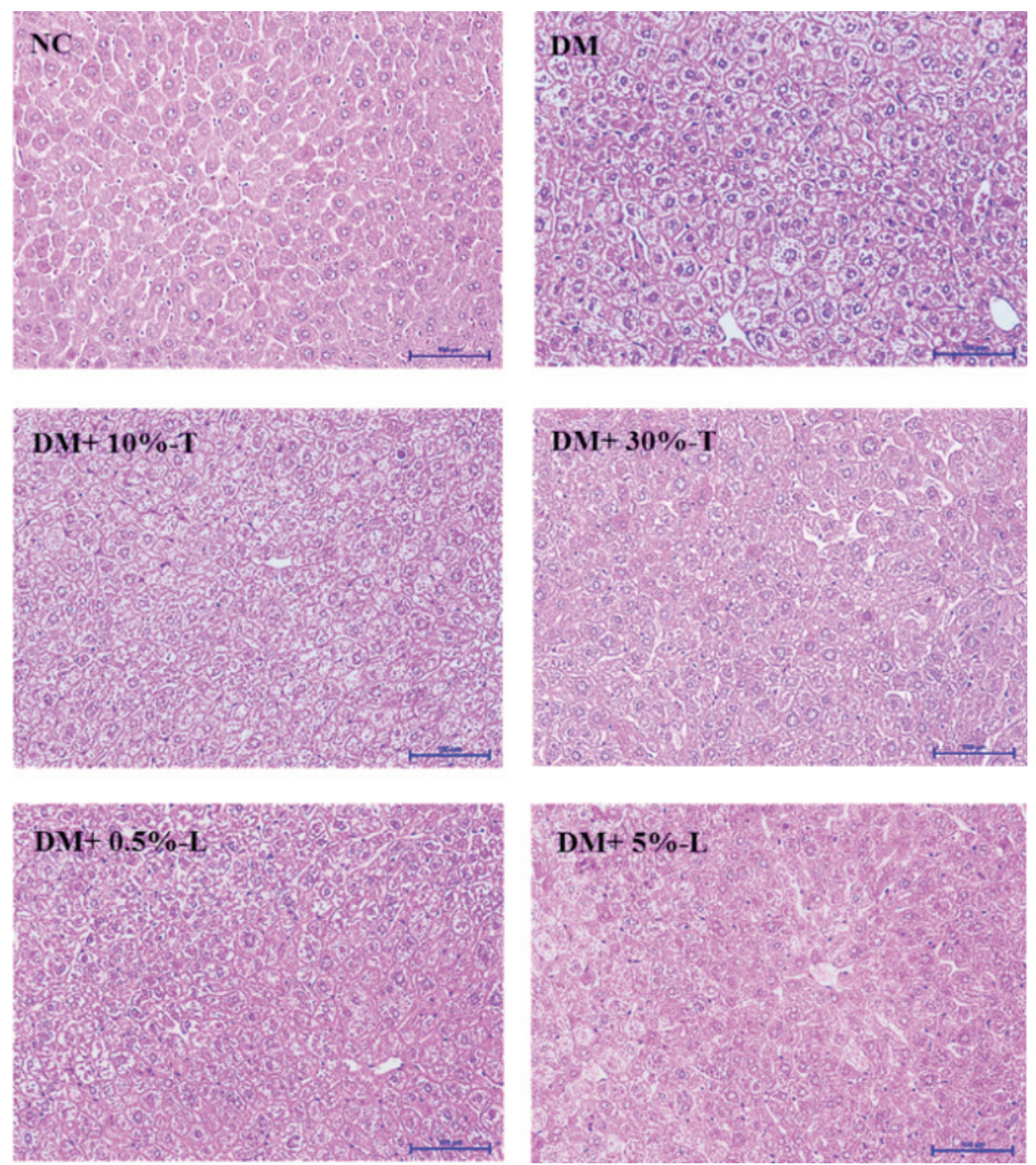

Fig. 3. Histochemical characterizations in liver tissues stained using hematoxylin and eosin after various experimental diet interventions. Scale bar length represents $100 \mu \mathrm{m}$ at 100× magnification. NC, normal control; DM, diabetes mellitus; DM+10\%-T, diabetes mellitus plus $10 \%$ tuber; DM+30\%-T, diabetes mellitus plus 30\% tuber; $\mathrm{DM}+0.5 \%$ - $\mathrm{L}$, diabetes mellitus plus $0.5 \%$ leaf; $\mathrm{DM}+5 \%-\mathrm{L}$, diabetes mellitus plus $5 \%$ leaf.

observed in the expression of the three candidate proteins in $\mathrm{NC}$ and $\mathrm{DM}$ mice. No significant differences were noted even in DM+10\%-T or DM+30\%WSP-T mice. By contrast, compared with other groups, after 8 weeks of treatment, $\mathrm{DM}+5 \%-\mathrm{L}$ mice demonstrated slight increases in the relative intensity of p-IR (by $24 \%$ ), p-Akt (by $18 \%$ ), and membrane GLUT4 (M-GLUT4; by 17\%). Thus, higher WSP-L dosage partially increased insulin sensitivity possibly via the insulin-signaling pathway and reduce blood glucose levels in diabetic mice.

\section{Discussion}

I. batatas L., also known as sweet potato with different varieties, is a valuable medicinal plant for the anticancer, antidiabetic, and anti-inflammatory activities in its extract $(36,37)$. In this study, mouse blood biochemistry indicated increased ALT, TG, and TNF- $\alpha$ levels resulting from increased free radical production caused by STZ in diabetic mice; however, these levels were significantly lower in mice who received the WSP-T or WSP-L intervention for 8 weeks. WSP leaves are rich in potent phytochemicals that can fight free radicals, and their roots are rich in dietary fiber; antioxidants and vitamins in them can also capture free radicals (36). Nevertheless, WSP-bioactive ingredients reduce not only blood glucose and insulin levels but also insulin resistance by improving the HOMA-IR index. In the preclinical phase of T2DM, insulin resistance is initially compensated for by increased insulin secretion; however, this prolonged overstimulation of insulin secretion causes the gradual failure of $\beta$-cells over time $(38,39)$. Therefore, in this study, Langerhans's area was significantly reduced in the diabetic 
(a)
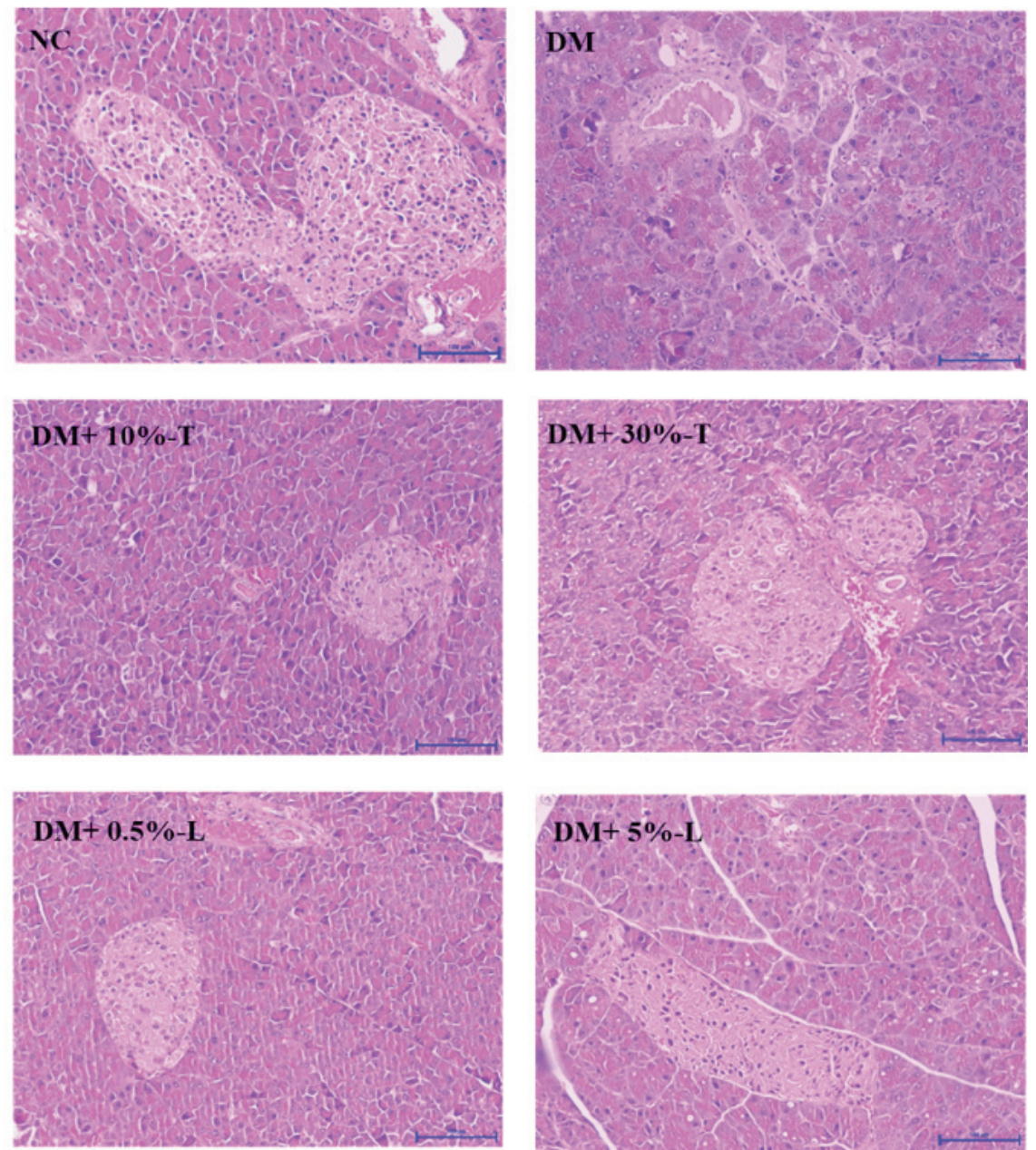

(b)

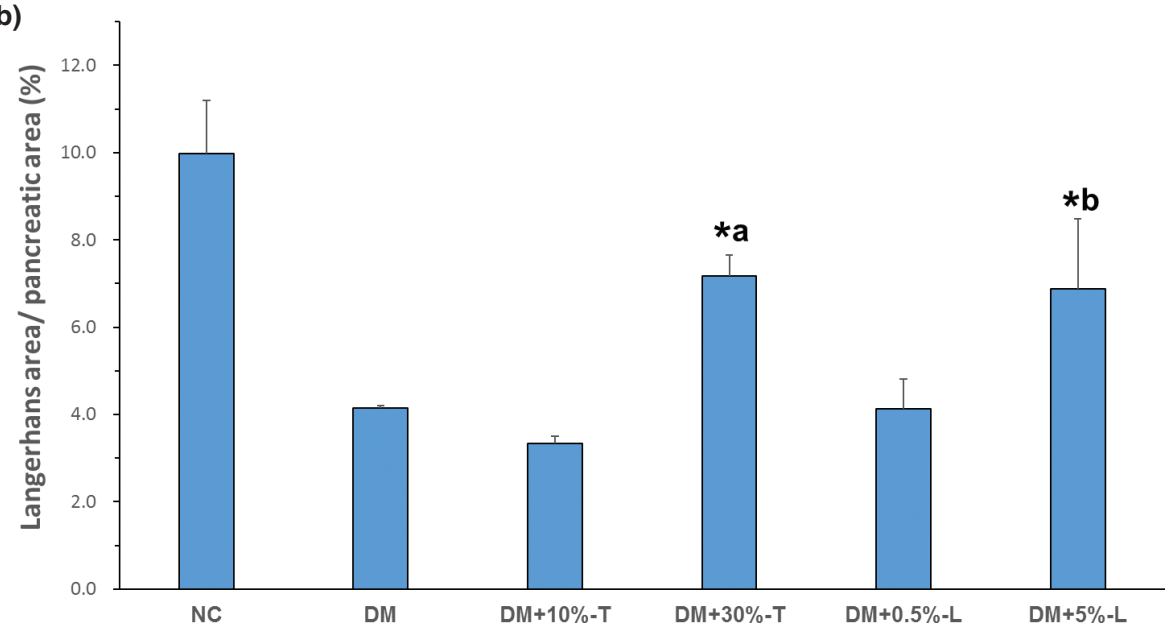

Fig. 4. Histochemical characterizations in pancreatic tissues stained using hematoxylin and eosin (H\&E) after various experimental diet interventions. Scale bar length represents $100 \mu \mathrm{m}$ at $100 \times$ magnification. (a) Morphological changes in pancreatic islets were observed through H\&E staining after the white sweet potato intervention. (b) The size of the Langerhans area in the photomicrographs was determined using ImageJ. Asterisks indicate significant difference compared to DM group. Letter ' $\mathrm{a}$ ' indicates significance level to $\mathrm{DM}+10 \%$-T group. Letter ' $\mathrm{b}$ ' indicates significance level to DM + 0.5\%-L group. All values are presented as means \pm standard deviations $(n=5)$. Statistical evaluation was performed using one-way ANOVA, followed by Duncan's multiple range test, $P<0.05$. 
(a)
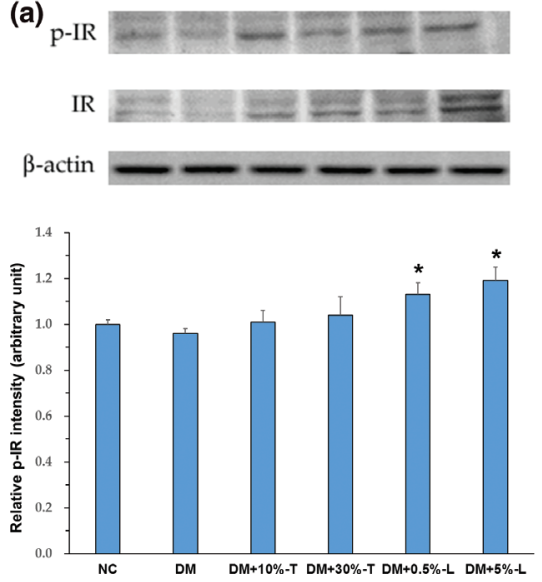

(b)
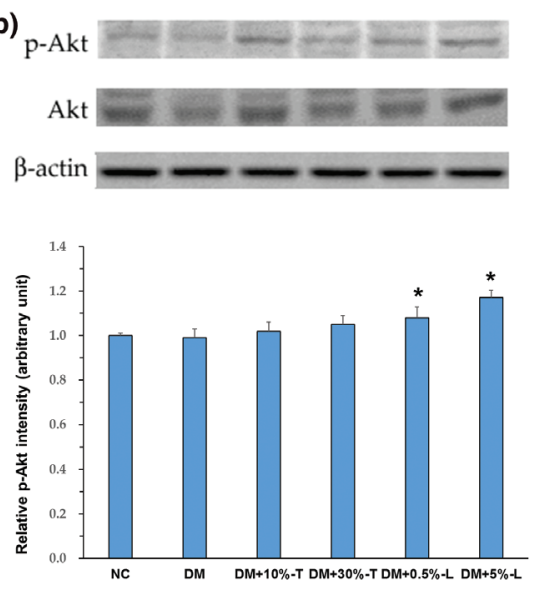

(c)
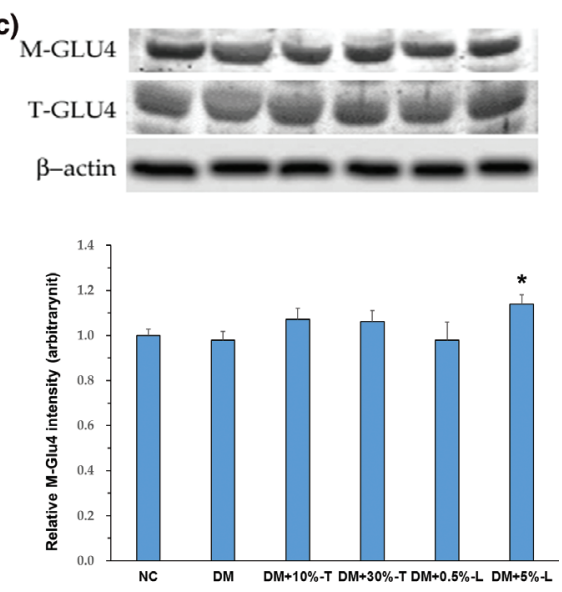

Fig. 5. Expression of insulin-signaling-related proteins in the muscle. Protein expression of p-IR \& IR (panel a), p-Akt \& Akt (panel b), and M-GLUT4 \& T-GLU4 (panel c) were analyzed with Western blotting of the homogenates in the gastrocnemius muscle. Data are expressed as means \pm standard deviations $(n=5)$. p-IR, phospho-insulin receptor; IR, insulin receptor; p-Akt, phospho-protein kinase B; Akt, protein kinase B; M-GLU4, membrane glucose transporter 4; T-GLU4, total glucose transporter 4; Asterisks indicate significant difference compared to DM group. Statistical evaluation was performed using one-way ANOVA, followed by Duncan's multiple range test, $P<0.05$.

group, but was significantly recovered by the $30 \%$ WSP-T or 5\% WSP-L intervention. The antidiabetic activity of WSP is partly due to the regeneration of pancreatic islets, which lowers the blood glucose level and its AUC. Our results are consistent with those of Sunarti et al. (40): pancreatic $\beta$-cell regeneration by white-skinned sweet potato (WSSP) in rats with STZ-induced diabetes might increase the number and size of islets and thus result in the formation of small new islets adjacent to the duct in pancreatic tissue.

In WSP roots or leaves, the major phytochemicals are flavonoids, terpenoids, tannins, saponins, glycosides, alkaloids, steroids, and phenolic acids $(37,41)$. Some medical plants are associated with regeneration of the Langerhans's area, and phytochemicals are thus used for the treatment of diabetes. The epigallocatechin gallate intervention can moderate the decrease in the islet mass induced by multiple low doses of STZ in mice (42). The flavonoid-rich fraction of Pilea microphylla can preserve the islet architecture and prevent hepatocyte hypertrophy based on the histopathology of the pancreas and liver in high-fat mice with STZ-induced diabetes (43). However, all WSP phenolic compounds responsible for the differences in the results warrant biological metabolite analysis to clarify blood sugar-lowering mechanisms.

The insulin-stimulated glucose uptake in skeletal muscle plays a major role in regulating glucose metabolism and energy homeostasis. Therefore, the targets of the PI3K/Akt pathway are critical because treatments of T2DM function involve the impairment of this signaling pathway in muscles, all of which causes hyperglycemia and insulin resistance $(10,15)$. Bae et al. reported that mulberry leaf extract reduced fasting blood glucose and insulin levels, enhanced insulin sensitivity, and increased p-Akt and p-AMPK expression in db/db mice (44). The hypoglycemic effect of Myrcia bella leaf extract in mice with STZ-induced diabetes can increase the expression of the insulin-signaling pathway involving PI3K/Akt proteins (45). In the current study, Western blotting indicated that $5 \%$ WSP-L slightly increased the p-IR, p-Akt, and M-GLUT4 expression, we speculate that the direct use of lyophilized and ground WSP-L may not effectively release biologically active substances, resulting in an insignificant PI3K/AKT signal expression in mice muscle tissue. In addition, AMPK-mediated hyperglycemia to insulin signal transduction was not present in our data, which needs more evidence to complete the antidiabetic mechanism by WSP-L.

According to Oki et al. (24), arabinogalactan isolated from the tuberous cortex of WSSP is an antidiabetic compound that can decrease the elevation in plasma glucose levels by reducing insulin resistance. The active component isolated from WSSP has a high molecular weight (24). In addition, resistant starch may be a promising dietary fiber for the preventing or managing diabetes and the related diseases. In humans, RS improves insulin resistance after chronic feeding through a mechanism involving changes to both adipose tissue and muscle metabolism (46). Additionally, we employed in vitro enzyme-digested WSP-T, which contained $0.36 \pm 0.05$ resistant starch and $48.0 \pm 1.8 \mathrm{mg} / 100 \mathrm{mg}$ slowly digestible starch (29). Therefore, the tuber active substances with antidiabetic effects, in relation to in vivo digestibility and glucose release rate, warrant an additional study. 


\section{Conclusions}

Insulin resistance and pancreatic islet dysfunction are the two features of T2DM. In this study, high dosage of WSP-T or WSP-L could significantly reduce fasting blood glucose levels, improving fasting glucose tolerance, lowering HOMA-IR, and regenerating pancreatic islets. Notably, among all concentrations of WSP-T or WSP-L used, the antidiabetic effects of a 5\% WSP-L may be slightly better in terms of insulin-signaling pathway activation. Finally, this study confirmed that whole WSP can be used to treat T2DM, by using experiments on mice with diabetes, biochemical analysis, histomorphometry, and insulin-signaling pathway analysis. Our results indicate that the hypoglycemic effect in different concentrations of WSP-T or WSP-L can be used as raw materials or materials for health food manufacturing in the food industry.

\section{Authors' contributions}

Sing-Chung Li, Chun-Kuang Shih, and Lie-Fen Shyur were responsible for the conceptualization of the study. All authors contributed to the methodology. Viola Varga, Liang-Chen Shih, and Peng-Ru Chen were responsible for data curation. Shu-Fang Lo was responsible for resources, Formal analysis was done by Sing-Chung Li, Chun-Kuang Shih, and Chiao-Ming Chen. Sing-Chung Li prepared the original draft. Chun-Kuang Shih and Chiao-Ming Chen performed the validation. Sing-Chung $\mathrm{Li}$ was responsible for the final approval of the version to be published.

\section{Ethical approval}

All applicable international, national, and institutional guidelines for the care and use of animals were followed.

\section{Acknowledgements}

This research was funded by the Council of Agriculture [105-Agricultural Science-13.3.1-Science-a6] and the Ministry of Science and Technology, Taiwan [NSC 101-2313-B-038-004-MY3].

\section{Conflicts of interest and funding}

The authors have not received any funding or benefits from industry or elsewhere to conduct this study.

\section{References}

1. Zimmet P, Alberti KG, Magliano DJ, Bennett PH. Diabetes mellitus statistics on prevalence and mortality: facts and fallacies. Nat Rev Endocrinol 2016; 12: 616. doi: 10.1038/ nrendo.2016.105.

2. Ogurtsova K, da Rocha Fernandes JD, Huang Y, Linnenkamp U, Guariguata L, Cho NH, et al. IDF Diabetes Atlas: global estimates for the prevalence of diabetes for 2015 and 2040. Diabetes Res Clin Pract 2017; 128: 40-50. doi: 10.1016/j. diabres.2017.03.024.
3. Shulman GI. Cellular mechanisms of insulin resistance. J Clin Investig 2000; 106(2): 171-6. doi: 10.1172/JCI10583.

4. Kahn SE, Hull RL, Utzschneider KM. Mechanisms linking obesity to insulin resistance and type 2 diabetes. Nature 2006; 444(7121): 840. doi: 10.1038/nature05482.

5. Hales CN, Barker DJJD. Type 2 (non-insulin-dependent) diabetes mellitus: the thrifty phenotype hypothesis. Diabetologia 1992; 35(7): 595-601. doi: 10.1093/ije/dyt133.

6. Leibowitz G, Kaiser N, Cerasi E. $\beta$-Cell failure in type 2 diabetes. J Diabetes Investig 2011; 2(2): 82-91. doi: 10.1111/j.2040-1124.2010.00094.x.

7. Szkudelski TJEb, medicine. Streptozotocin-nicotinamideinduced diabetes in the rat. Characteristics of the experimental model. Exp Biol Med 2012; 237(5): 481-90. doi: 10.1258/ ebm.2012.011372.

8. Masiello P, Broca C, Gross R, Roye M, Manteghetti M, Hillaire-Buys D, et al. Experimental NIDDM: development of a new model in adult rats administered streptozotocin and nicotinamide. Diabetes 1998; 47(2): 224-9. doi: 10.2337/diab.47.2.224.

9. Nakamura T, Terajima T, Ogata T, Ueno K, Hashimoto N, Ono K, et al. Establishment and pathophysiological characterization of type 2 diabetic mouse model produced by streptozotocin and nicotinamide. Biol Pharm Bull 2006; 29(6): 1167-74. doi: 10.1248/bpb.29.1167.

10. Huang X, Liu G, Guo J, Su Z. The PI3K/AKT pathway in obesity and type 2 diabetes. Int J Biol Sci 2018; 14(11): 1483. doi: 10.7150/ijbs.27173.

11. Minokoshi Y, Kahn CR, Kahn BB. Tissue-specific ablation of the GLUT4 glucose transporter or the insulin receptor challenges assumptions about insulin action and glucose homeostasis. J Biol Chem 2003; 278(36): 33609-12. doi: 10.1074/jbc. R300019200.

12. Costa MM, Violato NM, Taboga SR, Góes RM, Bosqueiro JR. Reduction of insulin signalling pathway IRS-1/IRS-2/AKT/ mTOR and decrease of epithelial cell proliferation in the prostate of glucocorticoid-treated rats. Int J Exp Pathol 2012; 93(3): 188-95. doi: 10.1111/j.1365-2613.2012.00817.x.

13. Copps K, White M. Regulation of insulin sensitivity by serine/threonine phosphorylation of insulin receptor substrate proteins IRS1 and IRS2. Diabetologia 2012; 55(10): 2565-82. doi: 10.1007/s00125-012-2644-8.

14. Govers R. Cellular regulation of glucose uptake by glucose transporter GLUT4. Adv Clin Chem 2014; 66: 173-240. doi: 10.1016/B978-0-12-801401-1.00006-2.

15. Saltiel AR, Kahn CR. Insulin signalling and the regulation of glucose and lipid metabolism. Nature 2001; 414: 799. doi: 10.1038/414799a.

16. Ishiki M, Klip A. Minireview: recent developments in the regulation of glucose transporter-4 traffic: new signals, locations, and partners. Endocrinology 2005; 146(12): 5071-8. doi: 10.1210/ en.2005-0850.

17. Naowaboot J, Pannangpetch P, Kukongviriyapan V, Prawan A, Kukongviriyapan U, Itharat A. Mulberry leaf extract stimulates glucose uptake and GLUT4 translocation in rat adipocytes. Am J Chin Med 2012; 40(01): 163-75. doi: 10.1142/ S0192415X12500139.

18. Hsu CY, Shih HY, Chia YC, Lee CH, Ashida H, Lai YK, et al. Rutin potentiates insulin receptor kinase to enhance insulindependent glucose transporter 4 translocation. Mol Nutr Food Res 2014; 58(6): 1168-76. doi: 10.1002/mnfr.201300691.

19. Zhang Y, Liu X, Han L, Gao X, Liu E, Wang T. Regulation of lipid and glucose homeostasis by mango tree leaf extract 
is mediated by AMPK and PI3K/AKT signaling pathways. Food Chem 2013; 141(3): 2896-905. doi: 10.1016/j. foodchem.2013.05.121.

20. Ying C, Mao Y, Chen L, Wang S, Ling H, Li W, et al. Bamboo leaf extract ameliorates diabetic nephropathy through activating the AKT signaling pathway in rats. Int J Biol Macromol 2017; 105: 1587-94. doi: 10.1016/j.ijbiomac.2017.03.124.

21. Moch. Saiful B, Hye won J, Jongwon C, Jong-Ok P. Protective effect of white-skinned sweet potato (Ipomoea batatas L.) from Indonesia on streptozotocin-induced oxidative stress in rats. J Life Sci 2010; 20(11): 1569-76. doi: 10.5352/ JLS.2010.20.11.1569.

22. Kusano S, Abe H, Tamura H. Isolation of antidiabetic components from white-skinned sweet potato (Ipomoea batatas L.). Biosci Biotechnol Biochem 2001; 65(1): 109-14. doi: 10.1271/ bbb.65.109.

23. Kusano S, Abe H. Antidiabetic activity of white skinned sweet potato (Ipomoea batatas L.) in obese Zucker fatty rats. Biol Pharm Bull 2000; 23(1): 23-6. doi: 10.1248/bpb.23.23.

24. Oki N, Nonaka S, Ozaki S. The effects of an arabinogalactan-protein from the white-skinned sweet potato (Ipomoea batatas L.) on blood glucose in spontaneous diabetic mice. Biosci Biotechnol Biochem 2011; 75(3): 596-8. doi: 10.1271/ bbb.100711.

25. Kusano S, Tamasu S, Nakatsugawa S. Effects of the whiteskinned sweet potato (Ipomoea batatas L.) on the expression of adipocytokine in adipose tissue of genetic type 2 diabetic mice. Food Sci Technol Res 2005; 11(4): 369-72. doi: 10.3136/ fstr.11.369.

26. Ludvik B, Hanefeld M, Pacini G. Improved metabolic control by Ipomoea batatas (Caiapo) is associated with increased adiponectin and decreased fibrinogen levels in type 2 diabetic subjects. Diabetes Obes Metab 2008; 10(7): 586-92. doi: 10.1111/j.1463-1326.2007.00752.x.

27. Ludvik B, Waldhäusl W, Prager R, Kautzky-Willer A, Pacini G. Mode of action of Ipomoea batatas (Caiapo) in type 2 diabetic patients. Metabolism 2003; 52(7): 875-80. doi: 10.1016/ S0026-0495(03)00073-8.

28. Ludvik BH, Mahdjoobian K, Waldhaeusl W, Hofer A, Prager R, Kautzky-Willer A, et al. The effect of Ipomoea batatas (Caiapo) on glucose metabolism and serum cholesterol in patients with type 2 diabetes: a randomized study. Diabetes Care 2002; 25(1): 239-40. doi: 10.2337/diacare.25.1.239.

29. Shih CK, Chen CM, Hsiao TJ, Liu CW, Li SC. White sweet potato as meal replacement for overweight white-collar workers: a randomized controlled trial. J Nutrients 2019; 11(1): 165. doi: 10.3390/nu11010165.

30. Chen C-M, Shih C-K, Su Y-J, Cheang K-U, Lo S-F, Li S-C. Evaluation of white sweet potato tube-feeding formula in elderly diabetic patients: a randomized controlled trial. Nutr Metab 2019; 16(1): 70. doi: 10.1186/s12986-019-0398-8.

31. Reeves PG, Nielsen FH, Fahey GC, Jr. AIN-93 Purified diets for laboratory rodents: final report of the American Institute of Nutrition Ad Hoc Writing Committee on the Reformulation of the AIN-76A Rodent Diet. Nutr 1993; 123(11): 1939-51. doi: 10.1093/jn/123.11.1939.

32. Shimizu R, Sakazaki F, Okuno T, Nakamuro K, Ueno H. Difference in glucose intolerance between C57BL/6J and ICR strain mice with streptozotocin/nicotinamide-induced diabetes. Biomed Res 2012; 33(1): 63-6. doi: 10.2220/biomedres.33.63.

33. Christensen SD, Mikkelsen L, Fels J, Bodvarsdottir T, Hansen A. Quality of plasma sampled by different methods for multiple blood sampling in mice. Lab Anim 2009; 43(1): 65-71. doi: 10.1258/la.2008.007075.

34. Lee B, Shi L, Kassel DB, Asakawa T, Takeuchi K, Christopher RJ. Pharmacokinetic, pharmacodynamic, and efficacy profiles of alogliptin, a novel inhibitor of dipeptidyl peptidase-4, in rats, dogs, and monkeys. Eur J Pharmacol 2008; 589(1-3):306-14. doi: 10.1016/j.ejphar.2008.04.047.

35. Cha DR, Zhang X, Zhang Y, Wu J, Su D, Han JY, et al. Peroxisome proliferator-activated receptor $\alpha / \gamma$ dual agonist tesaglitazar attenuates diabetic nephropathy in $\mathrm{db} / \mathrm{db}$ mice. Diabetes 2007; 56(8): 2036-45. doi: 10.2337/db06-1134.

36. Mohanraj R, Sivasankar S. Sweet potato (Ipomoea batatas [L.] Lam) - a valuable medicinal food: a review. J Med Food 2014; 17(7): 733-41. doi: 10.1089/jmf.2013.2818.

37. Ayeleso TB, Ramachela K, Mukwevho E. A review of therapeutic potentials of sweet potato: pharmacological activities and influence of the cultivar. Trop J Pharm Res 2016; 15(12): 2751-61. doi: 10.4314/tjpr.v15i12.31.

38. Lencioni C, Lupi R, Del Prato SJCdr. $\beta$-cell failure in type 2 diabetes mellitus. Curr Diabetes Rep 2008; 8(3): 179-84. doi: 10.1007/s11892-008-0031-0.

39. Prentki M, Nolan CJJTJoci. Islet $\beta$ cell failure in type 2 diabetes. J Clin Investig 2006; 116(7): 1802-12. doi: 10.1172/JCI29103.

40. Sunarti, Susilowati R, Royhan A . Effects of white-skinned sweet potato (Ipomoea batatas L.) on pancreatic beta cells and insulin expression in streptozotocin induced diabetic rats. Majalah Kesehatan Pharmamedika 2009; 1(2): 45-9. https://www. researchgate.net/publication/267987188.

41. Musilová J, Bystrická J, Árvay J, Harangózo LJP. Polyphenols and phenolic acids in sweet potato (Ipomoea batatas L.) roots. Slovak J Food Sci 2017; 11(1): 82-7. doi: 10.5219/705.

42. Song E-K, Hur H, Han M-K. Epigallocatechin gallate prevents autoimmune diabetes induced by multiple low doses of streptozotocin in mice. Archiv Pharm Res 2003; 26(7): 559-63. doi: 10.1007/BF02976881.

43. Bansal P, Paul P, Mudgal J, Nayak PG, Pannakal ST, Priyadarsini KI, et al. Antidiabetic, antihyperlipidemic and antioxidant effects of the flavonoid rich fraction of Pilea microphylla (L.) in high-fat diet/streptozotocin-induced diabetes in mice. Exp Toxicol Pathol 2012; 64(6): 651-8. doi: 10.1016/j. etp.2010.12.009.

44. Bae U-J, Jung E-S, Jung S-J, Chae S-W, Park B-H. Mulberry leaf extract displays antidiabetic activity in $\mathrm{db} / \mathrm{db}$ mice via Akt and AMP-activated protein kinase phosphorylation. Food Nutr Res 2018; 62: 1473. doi: 10.29219/fnr.v62.1473.

45. Vareda PMP, Saldanha LL, Camaforte NAdP, Violato NM, Dokkedal AL, Bosqueiro JR, et al. Myrcia bella leaf extract presents hypoglycemic activity via PI3k/Akt insulin signaling pathway. Evid Based Complement Alternat Med 2014; 2014: 543606. doi: 10.1155/2014/543606.

46. Robertson MD. Dietary-resistant starch and glucose metabolism. Curr Opin Clin Nutr Metab Care 2012; 15(4): 362-7. doi: 10.1097/ MCO.0b013e3283536931.

\footnotetext{
*Sing-Chung Li, PhD

School of Nutrition and Health Science

College of Nutrition

Taipei Medical University

250 Wu-Xin Street

Taipei, Taiwan I 031

Email: sinchung@tmu.edu.tw
} 